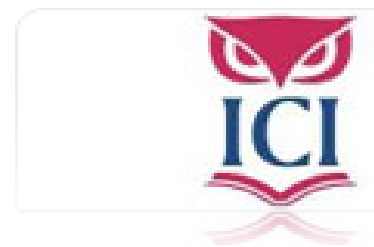

IUS. Revista del Instituto de Ciencias Jurídicas de Puebla A.C.

ISSN: 1870-2147

revista.ius@hotmail.com

Instituto de Ciencias Jurídicas de Puebla A. C.

México

Villabella Armengol, Carlos Manuel

Consideraciones sobre la forma de gobierno en Cuba

IUS. Revista del Instituto de Ciencias Jurídicas de Puebla A.C., núm. 21, 2008, pp. 168-192 Instituto de Ciencias Jurídicas de Puebla A. C.

Puebla, México 


\section{CONSIDERACIONES SOBRE LA FORMA DE GOBIERNO EN CUBA}

Carlos Manuel Villabella Armengol*

SUMARIO

1. Presentación

2. Precisiones conceptuales

3. Clasificación de las formas de gobierno

4. La forma de gobierno convencional

5. La forma de gobierno en el sistema socialista

6. La forma de gobierno en Cuba a tenor de la Constitución de 1976

\section{RESUMEN}

El presente artículo hace un análisis de la categoría forma de gobierno y destaca los diferentes enfoques de su conceptualización, adentrándose en particular en los rasgos de la forma de gobierno del extinto sistema socialista que perdura en la contemporaneidad en China, Corea del Norte, Cuba y Vietnam. Sobre esta disquisición aborda con detalle los rasgos de la forma de gobierno cubana que tanta incertidumbre y especulación genera.

\section{ABSTRACT}

The present article makes an analysis of the category it forms of government and it highlights the different focuses of its conceptualization, going into in particular in the features in the way of government of the extinct socialist system that it lasts at the present time in China, Korea of the North, Cuba, and Vietnam. On these reflections approach with detail the features in the Cuban government way that so much uncertainty and speculation generates.

\section{Presentación}

La Constitución es la vía por la que el poder político se formaliza institucionalmente, se legitima y adquiere fundamento legal, propósito que fue el fin del primer constitucionalismo escrito. Por ello, los textos constitucionales decimonónicos fueron breves y contaban con dos núcleos de

* Especialista en derecho constitucional y ciencia política por el Centro de Estudios Constitucionales de Madrid. Experto académico por la Universidad de Granada. Doctor en ciencias jurídicas por la Universidad de La Habana, miembro del Sistema Nacional de Investigadores de México. Integrante de la Directiva Nacional de la Sociedad Científica de Derecho Constitucional de Cuba. 
contenidos fundamentales, la organización del poder político (orgánica) y los derechos que los ciudadanos poseían frente él y se constituian en valladar del mismo (dogmática).

Progresivamente las constituciones se fueron abriendo a otros contenidos, se fueron cargando de contenidos que interesaban elevarse a su rango, cuestión por lo que es válida la imagen de que las mismas se erigen en el pacto de la sociedad consigo misma, concierto en el que estructura y vertebra el poder pero en el que también se establecen y jerarquizan aspectos para la organización de la sociedad en su conjunto. De esta manera, la Constitución deviene en hecho cultural, en documento que condensa su tiempo y su ámbito en ideas y conceptos.

A pesar de ello, puede afirmarse sin equivocación que la institucionalización del poder político sigue siendo el objeto central del derecho constitucional, lo que hace a través de la regulación de diferentes instituciones, algunas de las cuales sólo diagrama, mientras otras regula casi hasta el detalle.

Este último es el caso de la forma de gobierno, categoría de una gran polisemia por las diferentes dimensiones teóricas con que se ha manejado y los diferentes enfoques que ha tenido a lo largo del pensamiento político-constitucional, cuestión por lo cual no existe consenso en la explicitación de este concepto en la literatura especializada.

Sobre este contexto problemático desde el punto de vista teórico, abordar la forma de gobierno de lo que fue el socialismo este-europeo (si fuera posible hablar de una forma de gobierno única para estos países) o de los países que hoy se inscriben en ese sistema político, resulta como navegar entre Escilas y Caribdis. Por un lado, porque la postura generalizada de la teoría del Estado marxista fue de negación a la posibilidad de que las tipologías depuradas por la doctrina occidental fueran aplicables a esos países. Por otro, porque el abordaje de esta noción por parte de la bibliografía occidental es enfocada en general de manera esquemática, calificando la forma a través de la cualidad ideológica y acuñando que el socialismo es incompatible con la democracia. De esta manera, quedó enmarcada como modalidad de la forma autoritaria, dictatorial o totalitaria y sólo en alguna literatura más lúcida de derecho constitucional comparado ha quedado reconocida con independencia.

El debate académico sobre este aspecto volvió a cobrar actualidad cuando hace más de un año el mandatario de la República de Cuba transfirió por problemas de enfermedad sus poderes al vicepresidente del Consejo 
de Estado, con lo cual también la discusión sobre el futuro del sistema socialista cubano y las especulaciones sobre el inicio para este país de una "transición a la española" ocuparon espacios noticiosos.

Sobre este trasfondo se escribe el presente artículo, que persigue el objetivo de categorizar la forma de gobierno cubano y exponer sus rasgos esenciales.

\section{Precisiones conceptuales}

Una postura teórica de amplia aceptación en la doctrina es la que aborda la explicación de esta categoría al unísono del concepto forma de Estado, presentándose como términos entre los que se produce una relación discursiva del todo con una de sus partes y en donde las formas de gobierno quedan enmarcadas en determinadas formas de Estado.

Así, los estudiosos que se mueven en este supuesto, exponen que la forma de Estado es un concepto de mayor dimensión al expresar la manera de ser de la sociedad política como un todo, a partir de la específica articulación que tienen en ella los elementos de territorio, población y poder político; constituyendo así la expresión concreta a través de la cual se manifiesta un tipo histórico de Estado:

Utilizamos la expresión forma de Estado para indicar, de la manera más amplia, las diversas relaciones que unen entre sí los diversos elementos constitucionales de carácter tradicional del mismo Estado, sobre la base de concepciones específicas de carácter político-jurídico. ${ }^{1}$

El Estado es un término muy genérico que designa la totalidad de la comunidad política, a un conjunto de instituciones y de personas -gobernantes y gobernados- que forman una sociedad jurídicamente organizada sobre un espacio geográfico determinado; el vocablo gobierno en cambio, es mucho más restringido, comprende solamente la organización específica de los poderes constituidos al servicio del Estado, mismos que son, principalmente, los órganos legislativos, ejecutivo y judicial. ${ }^{2}$

${ }^{1}$ Paolo Biscaretti di Ruffia, Introducción al derecho constitucional comparado, Fondo de Cultura Económica, México, 2000, p. 114.

${ }^{2}$ Héctor Fix-Zamudio y Salvador Valencia Carmona, Derecho constitucional mexicano y comparado, 
Ambas formas se implican e influyen reciprocamente, en principio, toda forma de gobierno se encuadra en una forma más amplia que condiciona a la anterior, existe una concepción de fondo acogida por cada Estado en cuanto a sus bases económicas, sociales y políticas y a las directrices que inspiran su acción, esta concepción de fondo da forma al Estado e influye en concreto sobre la actuación de la forma de gobierno. ${ }^{3}$

En este plano, algunos autores introducen reflexiones que matizan la dimensión conceptual que se plantea. De esta forma, se sostiene que el concepto forma de Estado puede verse en latus sensus tal y como se ha descrito, pero el mismo tiene también un enfoque restringido en el cual se entiende por tal sólo al conjunto de órganos de poder constitucionales que actúan en un determinado ordenamiento, ${ }^{4}$ o los mecanismos a través de los cuales éstos conforman la voluntad estatal. ${ }^{5}$

En esta perspectiva y visto como concepto que describe una faceta de la forma de Estado, la categoría forma de gobierno aflora entonces como el subsistema que expresa el diseño estructural y funcional que adopta el poder político público dentro de un sistema político, describiendo el conjunto de instituciones superiores que ejercen la soberanía y conforman el mecanismo estatal así como las interrelaciones que se establecen entre ellas. En esta idea, la forma de gobierno es el núcleo del Estado expresado en la organización específica que adoptan los poderes constituidos:

Con la expresión forma de gobierno se suele indicar la recíproca posición en que se encuentran los diversos órganos constitucionales del Estado, tomando el vocablo gobierno no en el sentido lato que le es propio como elemento constitutivo del Estado, sino en otro más estricto que significa el conjunto sólo de las principales instituciones estatales. ${ }^{6}$

La forma de gobierno tiene relación con la especial modalidad

Porrúa, México, 2001, p. 235.

${ }^{3}$ Guiseppe de Vergottini, Derecho constitucional comparado, Espasa-Calpe, Madrid, 1985, p. 117.

${ }^{4}$ Cfr. Alessandro Pizzorusso, Lecciones de derecho constitucional, Vol. 1, Centro de Estudios Constitucionales, Madrid, 1984, pp. 17ss.

${ }^{5}$ Cfr. G. N. Manov, "Acerca del concepto de la forma de Estado", en Estudios científicos de la Universidad Estatal de Tadzhikla, No. 4, Vol. xı, 1956, p. 6.

${ }^{6}$ Paolo Biscaretti di Ruffia, Op. cit., p. 223. 
adoptada por los órganos directivos que formulan, expresan y realizan la voluntad del Estado. ${ }^{7}$

La forma de gobierno se examina generalmente como institución estatal-jurídica que determina las interrelaciones entre el jefe de Estado, el Parlamento y el Gobierno. ${ }^{8}$

Sobre esta línea de interpretación hay también autores que introducen otras aristas y con ello colorean el enfoque señalado. Así, se ha sostenido que el concepto forma de gobierno tal y como se ha expresado constituye una visión amplia del mismo, sin embargo en strictus sensus esta categoría evoca únicamente al llamado poder ejecutivo y el orden de su formación y configuración, existiendo incluso un enfoque aún más restringido que lo asocia sólo a la sección de órganos que dentro del Ejecutivo se reconocen con ese nombre. ${ }^{9}$

Bajo esta misma línea de pensamiento, un sector de la teoría decantó el concepto sistema de gobierno como noción que concretaba a la forma de gobierno, expresando el diagrama de flujo de los órganos superiores del poder, el funcionamiento de éstos, y el movimiento e interrelación de los diferentes eslabones del poder supremo:

El sistema de gobierno es el conjunto funcional de relaciones institucionales entre los órganos de administración y ejecución, es decir, de gobierno y los demás órganos de poder del Estado. Estamos haciendo referencia a la dinámica funcional del gobierno en sus relaciones de poder con el resto del aparato estatal. ${ }^{10}$

El sistema de gobierno hace referencia a la organización funcional de los órganos del poder político dentro de una forma determinada de gobierno [...] viene dado por la estructura institucional del mismo a través de la cual se aplica el método de dirección social del poder político [...] es el gobierno en movimiento. ${ }^{11}$

${ }^{7}$ Borja Rodríguez, Derecho político y constitucional, Fondo de Cultura Económica, México, 2000, p. 82. ${ }^{8}$ O. Zhidkov et al., Fundamentos de la teoría socialista del Estado y el derecho, Vol. 1, ENPES, La Habana, 1989, p. 70.

${ }^{9}$ Cfr. Juan Badía Fernando, Estudios de ciencia política, Tecnos, Madrid, 1985, p. 627.

${ }^{10}$ Julio Fernández Bulté, Teoría del Estado y del derecho, teoría del Estado, Félix Varela, La Habana, 2002, p. 88.

${ }^{11}$ Diego Cañizares Fernando, Teoría del derecho, Pueblo y Educación, La Habana, 1979, p. 210. 
Una postura académica más actual y discrepante de las reseñadas, reinterpreta las categorías forma de Estado y forma de gobierno y las presenta como subsistemas conceptuales que abordan el aspecto del poder político desde diferentes ópticas, esbozándose como secantes que se tocan en puntos pero no se superponen, entre las cuales no se produce el silogismo general-particular de la corriente de pensamiento descrita. ${ }^{12}$

Así, se reconoce que la forma de gobierno es la organización horizontal del poder en el ámbito de los detentadores superiores, mientras que la forma de Estado es la organización vertical dentro de una nación.

En este sentido puede señalarse, con ánimo de reconceptualización, que la forma de gobierno define la organización que adoptan las instituciones supremas del poder que ejercen las funciones legislativa, ejecutiva y de gobierno, el modo de formación de sus eslabones supremos, sus roles dentro del Estado, las competencias que poseen, la dinámica de interrelación que se establece entre los mismos y la forma mediante la cual se conforma y produce en ellos el proceso de toma de decisiones a través del cual se personifica la voluntad estatal, siendo la solución jurídica-institucional que adopta el poder político en una nación y que se sintetiza en un modelo organizacional determinado.

Por su parte, la forma de Estado es la distribución espacial del poder de acuerdo a las características territoriales del país, lo que se concreta en una división política y administrativa específica que diseña un sistema de órganos que van desde los poderes centrales hasta los locales, dibujando diferentes cuotas de poderes y competencia en función de la mayor o menor autonomía con que se organicen las unidades territoriales, las que finalmente se articulan sobre la base de determinados principios.

De esta manera, puede concluirse que la forma de gobierno describe la anatomía jurídico-formal del poder político y la forma de Estado la arquitectura geográfica del mismo, lo cual posibilita la comprensión y el entendimiento del modelo estatal-institucional y de su dinámica funcional.

Decantar estas categorías y reconstruir su dimensión conceptual como se ha intentado hacer, es importante porque ello permite colocar a las categorías forma de Estado y forma de gobierno como dos piezas teóricas

\footnotetext{
${ }^{12}$ Si lo expuesto hasta aqui dibuja un diagrama bastante complejo de conceptos y categorias en los que intervienen como planteábamos diferentes elementos, el cuadro se vuelve aún más policromático si agregamos otros términos que son utilizados por algunos autores de manera indistinta: sistema político, fórmula política, forma jurídica del Estado, forma política del Estado, estructura gubernamental, mecanismo estatal son algunos de estos preceptos.
} 
clave de la teoría del Estado y el derecho constitucional, a través de las cuales se posibilita el abordaje del poder político desde un punto de vista jurídico-formal y dinámico-funcional y se logra el estudio comparado del mismo.

\section{Clasificación de la forma de gobierno}

Si tratar de depurar o reenfocar el objeto de estudio de esta investigación es una tarea académica interesante, acendrar las clasificaciones acumuladas en la literatura es un reto debido a la disímil taxonomía que existe en ésta y a que sobre la misma existen reflexiones desde la antigüedad, lo que acumula un largo historial de pensamiento respecto al tema.

Si se analiza detalladamente puede reconocerse que los enfoques de la forma de gobierno han estado relacionados en la teoría con el modelo organizacional del poder, la estructuración funcional de los órganos superiores del mismo, los mecanismos de ejercicio de éste, el diagrama de los partidos políticos, la influencia de los grupos de presión, las cualidades democráticas, las formas de acceder a la función ejecutiva, la cantidad de personas que desempeñan esta función, etcétera.

De esta manera, se ha acumulado una diversidad de catalogaciones que han acuñado una terminología convencional y han provocado que se creen estereotipos alrededor de este aspecto, sin entenderse suficientemente que ésta es una temática dialéctica.

"El deseo de clasificar según criterios racionales de semejanza o diferencia, la multiplicidad de estados y sus tipos o formas de gobierno se presenta como algo más que la simple satisfacción de una curiosidad intelectual [...] Una exacta clasificación de los tipos de gobierno puede ayudar a la mejor comprensión [...] de los sistemas políticos [...] La necesidad de clasificar y valorar las sociedades estatales según su tipo de gobierno es tan antigua como el pensar político del hombre [...] dado que la insatisfacción con su propio orden político parece ser un rasgo esencial del hombre [...] dirigido a descubrir las ventajas cualitativas de cada forma." ${ }^{13}$

Es por esa razón que en este parágrafo presentamos esquemáticamente algunas de las clasificaciones que se han realizado a través de lo que puede ser lo más prominente del pensamiento clásico, medieval y moderno, este último a partir de autores referentes.

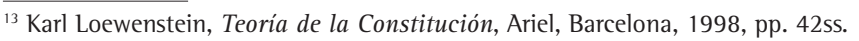


Del pensamiento antiguo se destacan los aportes de Platón (428-347 a. C.), Aristóteles (384-322 a. C.) y Cicerón (106-43 a. C.). ${ }^{14}$

Platón en La república clasificó a los gobiernos en monarquía, aristocracia y democracia. Aristóteles en La política planteó la que quizás ha sido la más conocida y seguida de las clasificaciones, en donde agrupó a los gobiernos por sus formas puras e impuras, encontrándose entre los primeros a la monarquía, la aristocracia y la democracia, mientras en los segundos a la tiranía, la oligarquía y la oclocracia.

Cicerón en De res publica esbozó la combinación de diferentes formas dando lugar al primer enfoque de un modelo de gobierno mixto.

Del pensamiento tardomedieval y renacentista son muy manejadas las clasificaciones de Santo Tomás de Aquino (1225-1274), Maquiavelo (14671527), John Locke (1632-1704) y Montesquieu (1689-1755). ${ }^{15}$

Tomás de Aquino en Summa Theologiae reconoció a la monarquía, la aristocracia, la oligarquía, la democracia y la tiranía. Maquiavelo en $E l$ principe habló de república y principado o monarquía. Locke en Tratado sobre el gobierno civil distinguió a la república, la oligarquía y la monarquía. Montesquieu en el El espiritu de las leyes trató de plantear un diagrama en donde se combinara lo cuantitativo y lo cualitativo, agregándole principios morales a sus tipos de gobierno. De esta manera, señaló a la democracia con virtud, la aristocracia con moderación, la monarquía con honor y el despotismo como modalidad impura.

A partir de la modernidad la catalogación comienza a presentar un cuadro más heterogéneo debido a que cada autor asume diferentes variables como base del análisis. Es por eso que sólo presentaremos algunas de ellas a través del pensamiento de importantes constitucionalistas y politólogos.

Maurice Duverger en Instituciones politicas y derecho constitucional ${ }^{16}$ realiza su estudio agrupando a los gobiernos de régimen de democracia liberal, de régimen autoritario capitalista (monarquías, dictaduras de partido único y dictaduras militares) y de régimen de dictadura socialista.

George Burdeau en Derecho constitucional e instituciones politicas ${ }^{17}$ distinguió el régimen democrático (parlamentario, presidencial, de asam-

\footnotetext{
${ }^{14} \mathrm{Cfr}$. Norberto Bobbio, Teoría de las formas de gobierno en la historia del pensamiento político. Años académicos 1975-1976, Fondo de Cultura Económica, México, 1996.

${ }^{15} \mathrm{Cfr}$. Karl Loewenstein, $\mathrm{Op}$. cit.

${ }^{16}$ Cfr. Maurice Duverger, Instituciones politicas y derecho constitucional, Ariel, Barcelona, 1992.

${ }^{17}$ Cfr. George Burdeau, Derecho constitucional e instituciones politicas, Editora Nacional, Madrid, 1981.
} 
blea), el régimen autoritario (cesarismo empírico, dictadura ideológica) y el régimen de poder individualizado

Karl Loewenstein en Teoría de la Constitución ${ }^{18}$ establece lo que él denomina una clasificación sociológica válida para superar las clasificaciones tradicionales de los estados, consistente en gobierno de democracia constitucional (gobierno de democracia directa, gobierno de asamblea, gobierno parlamentario, gobierno de gabinete, gobierno presidencial y gobierno directorial) y gobierno de autocracia (monarquía absoluta, cesarismo plebiscitario y neopresidencialismo).

Guiseppe de Vergottini, en Derecho constitucional comparado, ${ }^{19}$ recrea clasificaciones establecidas por otros autores y señala varias modalidades, entre ellas las de Estado de derivación liberal o de democracia clásica (monarquía constitucional, república presidencialista, gobierno parlamentario con predominio asambleario, gobierno parlamentario con preeminencia del gobierno, gobierno parlamentario con liderazgo del primer ministro, gobierno parlamentario con predominio del presidente y gobierno semipresidencialista), Estado socialista, Estado autoritario, Estado totalitario, Estado dictatorial y Estado subdesarrollado.

Paolo Biscaretti di Ruffia en Introducción al derecho comparado ${ }^{20}$ plantea como formas de gobierno a los estados de democracia clásica u occidental (monarquía, república presidencial, república parlamentaria, república constitucional directorial), Estado socialista y Estado autoritario.

Héctor Fix-Zamudio, en Derecho constitucional mexicano y compara$d o^{21}$ reconoce la clasificación de régimen parlamentario (monista-dualista, inorgánico-racionalizado, de gabinete-parlamentario bipartidista o de gabinete-parlamentario multipartidista), régimen presidencial (dentro del que ubica al semipresidencialismo), régimen de confusión de poderes (de asamblea o convencional), régimen democrático (modelo mayoritario y de consenso) y régimen autoritario (autoritarios tradicionales, totalitarios, autoritarios en el sentido estricto).

Gonzalo Reyes Salas en Sistemas políticos contemporáneos ${ }^{22}$ trata de establecer una clasificación abarcadora que tiene en cuenta todas las variables. De acuerdo a las instituciones formales internas existe el sistema

${ }^{18}$ Cfr. Karl Loewenstein, Op. cit.

${ }^{19}$ Cfr. Giusseppe de Vergottini, $O p$. cit.

${ }^{20} \mathrm{Cfr}$. Paolo Biscaretti di Ruffia, Op. cit.

${ }^{21}$ Cfr. Héctor Fix Zamudio et al., Derecho constitucional mexicano y comparado, Porrúa, México, 2001, p. 235.

${ }^{22}$ Cfr. Salas Reyes, Sistemas políticos contemporáneos, Ed. Oxford, México, 2000. 
presidencial, el parlamentario y el híbrido o semipresidencial. De acuerdo a las instituciones informales o factores reales del poder se distinguen el régimen dependiente y el interdependiente. De acuerdo a las instituciones de participación política indirecta se reconoce el sistema competitivo y el no competitivo. De acuerdo a las instituciones de participación política directa, existe el sistema de práctica plebiscitaria y el sistema de práctica de referendo.

La literatura de teoría marxista de los años ochenta ${ }^{23}$ del siglo xx reconoció a la forma de gobierno monárquica, la republicana (que a su vez agrupaba, según el sistema de gobierno, en parlamentaria, presidencial y semipresidencial) y la socialista (que catalogaba en república soviética y democracia popular).

Como se puede apreciar en un análisis diacrónico, desde los pensadores de la antigüedad hasta el siglo xvi la inmensa mayoría de los estudiosos señalaban como las modalidades básicas de las formas de gobierno a la monarquía y la democracia o república, las que se explicaban generalmente como "el gobierno de uno" y "el gobierno de muchos", sin contar el aporte de Aristóteles de que cualquier modalidad puede degenerarse y con ello cambiar su dinámica aunque la fisonomía siga siendo la misma.

Esto es lógico si se tiene en cuenta que el item de discriminación los constituía preponderantemente la arquitectura de la máxima magistratura y la forma de acceder a ella, de allí que el elemento numérico aflorara como la cuestión determinante.

De esta manera, la aporía en las mismas se explicaba a partir de que en la primera el poder político estaba concentrado en manos de una persona que accedía a él de manera hereditaria y lo ejercía según su parecer, mientras en la segunda el poder era compartido entre diferentes órganos que eran conformados de manera electiva y el mismo era ejercido de conformidad con leyes:

Las diferencias entre el jefe de Estado de las Monarquías y el de las Repúblicas estriban, como se ha visto, en el distinto origen

\footnotetext{
${ }^{23}$ Cfr. O. Zhidkov, et al., Op. cit., G. N. Manov, "Acerca del concepto de la forma de Estado", en Estudios cientificos de la Universidad Estatal de Tadzhikla, Vol. xı, No. 4, 1956; V. Popkov, "Formas del Estado socialista”, en Manual de teoría del Estado y el derecho; M. N. Marchénco, J. Fernández Bulté, Pueblo y Educación, La Habana, 1988; L. Grigorian; Y. Dolgopolov, Fundamentos del derecho estatal soviético, Progreso, Moscú, 1979. Manov, et al., Teoría marxista leninista del Estado y el derecho, Ciencias Jurídicas, La Habana, 1988; J. Fernández Bulté, Teoría del Estado y del derecho, teoría del Estado, Félix Varela, La Habana, 2002; Diego Cañizares Fernando, Teoría del derecho, Pueblo y Educación, La Habana, 1979.
} 
y título del poder -herencia, elección- y en el carácter que el poder mismo imprime a los respectivos magistrados: mayestático en la monarquía; un poder personal que persiste, o sea poder de una persona física que lo ejerce de por vida. En las Repúblicas el Presidente no pierde la cualidad de ciudadano, ni el serlo imprime carácter a la personalidad civil y política del que desempeñe el cargo, ni a su familia (no hay dinastía). Además la responsabilidad del Presidente tiene una consideración constitucional distinta a la del Monarca. ${ }^{24}$

En la actualidad no es posible sostener que estas dos variantes de organización y ejercicio del poder sean ambivalentes, ni siquiera que cada una de ellas sea en sí misma una forma de gobierno. De esta manera, en el diseño institucional-funcional del poder político moderno juegan un resorte más determinante la interrelación entre los órganos supremos del poder, las formas de controles y balances que entre los mismos se instrumentan y los roles que cada uno juega en la conformación de la voluntad estatal.

Es desde esta perspectiva que puede plantearse que las formas de gobierno contemporáneas son la parlamentaria, con sus vertientes monárquica y presidencial, la presidencial, la semipresidencial y la convencional, cada una de ellas con matices propios en los diferentes países.

De éstas, el diagrama funcional de la forma de gobierno convencional fue el prototipo sobre el que se estructuró de alguna manera la forma de gobierno de los países socialistas, cuestión por la cual comentamos sus características.

\section{LA FORMA DE GOBIERNO CONVENCIONAL}

$\mathrm{Al}$ estudiar esta forma de gobierno reconocida también por algunos autores como directorial, ${ }^{25}$ hay que acotar de manera inmediata que constituye un sistema sui generis que en la actualidad se manifiesta de manera exclusiva en Suiza, la cual es su prototipo, por lo que es manejado en la

${ }^{24}$ Adolfo Posada citado por Juan Schneider, "El régimen parlamentario", en Manual de derecho constitucional, Instituto Vasco de Administración Pública / Marcial Pons, Madrid, 1996, p. 234.

${ }^{25}$ Algunos estudiosos destacan que es incorrecto reconocer a este modelo como un sistema directorial porque esa denominación en strictus sensus correspondería a un mecanismo cuyos miembros no desempeñen en lo individual ninguna función y en el caso de Suiza los consejeros dirigen cada uno un departamento administrativo en el que, como se ha planteado, toman decisiones unipersonales. Cfv. García Pelayo, $O p$. cit., pp. 563ss. 
literatura especializada como marginal o de laboratorio, no abordándolo de hecho muchos estudiosos cuando reseñan las formas de gobierno en el derecho constitucional comparado.

La misma nace en Francia, crisol de modelos para el derecho constitucional moderno. Su primer antecedente es la Constitución de 1792, que al decretar el fin de la monarquía constitucional creó la Convención Nacional como órgano que reunía los poderes legislativos y ejecutivos, de cuyo seno se elegía al Consejo Ejecutivo integrado por 24 miembros y encargado de la dirección y vigilancia de la administración y de la ejecución de las leyes.

Posteriormente, la Constitución del año III (1795) instituyó un órgano ejecutivo integrado por cinco miembros que se denominó Directorio, el cual era elegido por la asamblea legislativa bicameral.

A este texto, continuó la Constitución del año vIII (1799) que conformó un gobierno reconocido como Consulado, integrado por tres personas elegidas por el cuerpo legislativo entre las que predominaba por sus atribuciones el primer cónsul, a la sazón, Napoleón Bonaparte.

Estas experiencias llegan a la Confederación de las Trece Comarcas que posteriormente constituirán la actual Suiza de manera directa con la intervención francesa de 1797 a 1815, adoptándose en la Constitución del año 1798 y retomándose de nuevo en el texto de 1848 .

Este sistema se adoptó también en Uruguay de 1917 a 1933 y luego de 1951 a $1966^{26}$ por coyunturas muy específicas.

Suiza es una nación de lenta evolución que hasta el siglo xIII constituía un conglomerado de pequeños estados en alianza que avanzan en sus relaciones hasta que en el xvi se integran en la Confederación de las Trece Comarcas.

Su historia constitucional, con un total de seis textos, comienza con la invasión francesa protagonizada a fines de 1797 y la informan el texto de 1798 que se inspira en la Constitución francesa de 1795 e introduce

\footnotetext{
${ }^{26}$ El presidente uruguayo José Battle y Ordóñez, del Partido Colorado, luego de culminar su primer mandato viajó a Suiza en donde estudió de cerca la forma de gobierno convencional y a la culminación de su segundo periodo presidencial logra imponer un texto constitucional en 1917 que instaura este modelo de gobierno mediante la existencia de un presidente electo por cuatro años que ejerce su magistratura compartiendo atribuciones con un Consejo Nacional de Administración conformado por nueve miembros, estructura que perduró hasta 1933, cuando fue echada abajo por golpe de Estado. Se introduce de nuevo en 1951 mediante un Consejo Nacional de Gobierno electo por cuatro años de manera directa y compuesto por nueve miembros de los cuales uno cada año asumía su presidencia. En ambos casos, tres de los nueve miembros pertenecian a la oposición. Esta segunda experiencia culminó en 1966, cuando se adoptó nuevamente la forma de gobierno presidencial. Cfr. Espiell Gross, Las constituciones del Uruguay, Madrid, 1978.
} 
la forma de gobierno convencional, el Acta de Mediación de 1803 que restaura la estructura confederada negada por el texto anterior y motivo de grandes conflictos entre federalistas y unitarios, el Pacto Confederal de 1815 por el cual se configura el actual mapa territorial, la Constitución de 1948 que representa la culminación del proceso revolucionario burgués y con ello el inicio de la historia moderna de esa nación, el texto de 1974 que nace producto de una revisión total de la anterior y la Constitución de 1 de junio del 2000.

Para entender cómo esta singular forma de gobierno se ha enraizado en Suiza, es necesario comprender la historia de esta nación que emerge como culminación de un proceso de unificación de las comarcas, encontrándose en los marcos de la federación el ámbito de convivencia y respeto necesario para la subsistencia de las particularidades socioculturales de un Estado plurinacional, multilingüístico y de diversidad religiosa, que sin embargo ha logrado una gran estabilidad política y encontrado la fórmula adecuada para su coexistencia social. ${ }^{27}$

Como resulta imposible hablar de esta forma de gobierno en abstracto, caracterizamos la misma únicamente a través del ejemplo suizo, el que posee los siguientes rasgos:

1. La función legislativa está en manos del Parlamento Federal, el que además se instituye como el órgano supremo del poder en el andamiaje estatal, sentido en el cual posee atribuciones que en otro esquema estatal corresponderían a otros órganos (conformar la política exterior, asegurar la política interior, ejercer el control sobre la actividad de gobierno y administración, decidir sobre conflictos de jurisdicción entre la autoridades federales, etc.).

Eso permite que se le reconozca como la institución que marca el indirizzo politico del sistema organizacional.

27 1) Estado plurinacional con cuatro lenguas oficiales: alemán (65\% de la población), francés (18\%), italiano (10\%) y romanche (1\%). 2) Diversidad religiosa conformada fundamentalmente por católicos $(46 \%)$ y protestantes (40\%). 3) Federalismo dual cooperativo en donde la periferia (los cantones) son el centro de la estructura territorial. 4) Estructuración del sistema político sobre la base de una arraigada concepción de participación en la vida política que canalizan a través de diversos mecanismos de democracia directa y semidirecta, como el ejercicio directo del poder soberano mediante reuniones de toda la población en donde se toman las decisiones más importantes para el cantón (landgemeinde), el referendo tanto en materia constitucional como legislativa, la iniciativa legislativa, la revocación de mandatos a los legisladores y miembros del Ejecutivo, etc. 5) Política exterior basada en la neutralidad, derivada del entendimiento de que su supervivencia como nación compuesta por un mosaico cultural y de credo consistía en no tomar parte en los conflictos que durante mucho tiempo se desarrollaron en Europa por motivos religiosos y nacionales. Este principio fue reconocido en el Congreso de Viena celebrado entre 1814 y 1815 que delimitó la actual geografía de fronteras europea y ratificado en el Tratado de Versalles de 1919. 
2. La función ejecutiva es desempeñada por un órgano colegiado denominado Consejo Federal integrado por siete miembros y que constituye la más alta autoridad ejecutiva y de gobierno, actuando como cuerpo colectivo. Esto conforma el rasgo esencial de esta forma de gobierno.

Este órgano posee iniciativa legislativa, promulga las leyes y puede legislar mediante trámite de urgencia en las materias en las que haya sido autorizado por el Parlamento. Sin embargo, no puede vetar las decisiones de la Asamblea.

3. El Consejo Federal es elegido por el Parlamento Federal y sus integrantes no pueden ser miembros del mismo.

No se integra fundamentalmente a tenor de las mayorias partidistas, sino que se tienen en cuenta también criterios de representación nacional tendientes a lograr una integración que refleje el mosaico cultural y territorial de la nación.

Es así que cuando se logra un adecuado equilibrio de los miembros del órgano, esta composición suele mantenerse reeligiendo a los consejeros que tienen un buen desempeño. De esta manera se señala que es uno de los Ejecutivos más estables de Europa y que "los sillones ministeriales suizos son los más seguros de Europa." ${ }^{28}$

4. Como órgano de gobierno cada miembro del Consejo a su vez preside un ramo de la administración. En el modelo original, éstos no podían tomar decisiones de manera independiente teniendo que ser todas adoptadas de forma colegiada, pero modificaciones introducidas en los inicios del siglo xx le han brindado mayor autonomía posibilitándole incluso que regulen aspectos relativos a sus departamentos ministeriales.

5. El Consejo es subordinado al Parlamento y se proyecta como agencia suya, ejerciendo este último el control y supervisión del mismo. No obstante, no se configura el instituto de responsabilidad política, ya que el Consejo no está obligado a presentar su programa de gobierno, no hay investidura y el Parlamento ejerce sólo mecanismos de control generales que no desembocan en la dimisión de los miembros del órgano.

En caso de objeción a alguna política del gobierno, el consejero implicado o el Consejo en pleno están obligados a cambiar de rumbo, pero no le está permitido dimitir.

6. El Consejo elige entre sus miembros a un presidente y un vicepresidente, los que fungen como presidente y vicepresidente de la Confe-

${ }^{28}$ Juan de Dios Gutiérrez Baylón, "Mitos y realidades del constitucionalismo suizo”, Lex de Julio, No. 1, 1995, pp. 15ss. 
deración. Éstos son elegidos por el término de un año y no pueden ser reelegidos para tal desempeño de inmediato.

En realidad no puede reconocerse que el presidente sea un jefe de Estado, sino más bien un primus interpares del órgano, evidenciándose en que incluso cuando viaja al extranjero en funciones de representación del país no suele hacerlo solo.

Por otra parte, está capacitado sólo para resolver de manera unipersonal cuestiones formularias o urgentes, sometiendo luego sus decisiones a la ratificación del Consejo.

9. El Parlamento no puede ser disuelto por el Consejo en ninguna circunstancia.

Como se puede observar, la espiga central de esta forma de gobierno estriba en que no se materializa la división de poderes tal como está concebida teóricamente bajo el esquema liberal burgués de Montesquieu, conformando por el contrario un diagrama funcional que se ha dado en llamar sistema de confusión de poderes o régimen de predominio de asamblea: "el tipo de gobierno directorial suizo es una forma política no susceptible de ser imitada, surgida de un pueblo políticamente maduro, socialmente homogéneo y con temperamento estable y sobrio". ${ }^{29}$

\section{LA FORMA DE GOBieRnO EN EL SISTEMA SOCIALISTA}

Pretender abordar la forma de gobierno de los países de sistema político socialista es como navegar entre Escilas y Caribdis. Por un lado, la postura generalizada de la teoría del Estado marxista fue de una negación a la posibilidad de que las tipologías depuradas por la doctrina occidental burguesa fueran aplicables a esos países: "La división de las repúblicas en presidenciales y parlamentarias no puede aplicarse [...] a los países socialistas. Aunque en varios de ellos [...] existe el cargo de presidente." ${ }^{30}$

Algunos autores o teóricos han querido asimilar esas formas de gobierno, bien al sistema parlamentario, bien al sistema presidencialista, apelando, en una u otra tendencia, a la existencia de innegables rasgos en la forma de esos gobiernos socialistas que, de alguna manera, los aproximan a los aludidos sistemas capita-

${ }^{29}$ Karl Loewenstein, Op. cit., pp. 144ss.

${ }^{30}$ O. Zhidkov, V. Chirkin, Y. Yudin, Fundamentos de la teoría socialista del Estado y el derecho, Vol. 1, ENPES, La Habana, 1989, p. 72. 
listas. Sin embargo, apenas se analizan las cosas con un poco de detenimiento se advierte que esas inclusiones son absolutamente forzadas y falsas. ${ }^{31}$

Por el otro flanco, el abordaje de esta noción por parte de la bibliografía occidental es enfocado en general de manera esquemática, calificando la forma a través de la cualidad ideológica y acuñando que el socialismo es incompatible con la democracia. De esta manera, queda enmarcada por muchos autores como modalidad de la forma autoritaria, dictatorial o totalitaria; sólo la literatura más lúcida de derecho constitucional comparado ha reconocido con independencia la forma de gobierno socialista.

Ciertamente resulta difícil aplicar el instrumental conceptual generado por la teoría occidental para estudiar y clasificar el poder público de los países socialistas, en tanto ambos sistemas parten de concepciones en torno al poder político diferentes y en consecuencia su diseño institucional se estructura sobre pivotes dispares y organiza sobre la base de principios disímiles. Pero amén de ello, también es real que la teoría socialista esquivó este esfuerzo rechazando de manera casi dogmática el sistema categorial burgués y condensando la idea de "atipicidad" de su forma de gobierno.

A pesar de encontrar reflexiones, como que: "no puede hablarse de una forma específica y menos exclusiva del Estado socialista [...] no sólo en la actualidad [...] sino incluso cuando [el socialismo] existía era imposible establecer un modelo funcional y estructural de gobierno propio del tipo de Estado socialista", ${ }^{32}$ en realidad la doctrina generada hasta los ochenta reconoció sólo como formas del tipo de Estado socialista a la República de los Soviets en la uRss y la República Democrático-Popular ${ }^{33}$ en Europa. De ellas se señalaban básicamente dos distinciones, el hecho de que en las últimas funcionó una pluralidad de partidos vinculados en un frente popular o nacional ${ }^{34}$ y la cuestión de que en muchos de estos países per-

\footnotetext{
31 Julio Fernández Bulté, Teoría del Estado y del derecho, teoría del estado, Félix Varela, La Habana, 2002, p. 105.

32 Ibid., p. 100.

${ }^{33}$ Cfr. M. N. Marchénco, J. Fernández Bulté, et al., Manual de teoría del Estado y el derecho, Pueblo y Educación, La Habana, 1988; Diego Cañizares Fernando, Teoría del derecho, Pueblo y Educación, La Habana, 1979. Esta clasificación también la repitió alguna bibliografía occidental. Cfr. Maurice Duverger, Instituciones politicas y derecho constitucional, Op . cit.; Paolo Biscaretti di Ruffia, Introducción al derecho constitucional comparado, Op. cit.

${ }^{34}$ Frente Democrático de Albania, Frente Patriótico de Bulgaria, Frente Nacional de los Checoslovacos y Eslovacos, Frente Nacional de Alemania, Movimiento Patriótico para el Renacimiento Nacional de Polonia, Frente de la Democracia y de la Unidad Socialista de Rumania, Frente Nacional Patriótico de Hungría, Alianza Socialista del Pueblo Trabajador de Yugoslavia.
} 
duraron instituciones estatales "de esencia burguesa" no coincidentes con la organización institucional que estructuraba el prototipo soviético.

De igual manera se reconocía en la literatura las peculiaridades históricas, ambientales y sociológicas de los diferentes países socialistas, las que debían de proporcionar especificidades en la morfología del poder de los mismos. Pero en puridad, tampoco hubo una concienzuda reflexión al respecto.

Incluso, aunque nunca existió una total similitud en los modelos estatales de los diferentes países, destacándose incluso ejemplos como el de Yugoslavia, que mantuvo una línea filosófica y práctica en la construcción de su sistema bastante distante de la soviética, lo cierto es que a partir de la década de los cincuenta hubo una tendencia de uniformidad institucional a partir del patrón soviético que quedó legitimada en las constituciones que se promulgaron por esa época. ${ }^{35}$

A ésta, luego le continuó otra etapa en donde se trató de acendrar de mejor manera las particularidades de cada nación mediante una nueva oleada constitucional. ${ }^{36}$

Finalmente hay que agregar que cuando se abordaban los rasgos de la forma de gobierno socialista en muchos autores se producían equívocos al entremezclar algunos rasgos que ciertamente son expresión de esta categoría con otros elementos. Así, es posible encontrar entre las características que se señalaban y que nada tenían que ver con la esencia de este concepto a la forma estatal unitaria, el unicameralismo del cuerpo legislativo, el principio de centralismo democrático, el régimen de democracia socialista o el principio de legalidad, etcétera. ${ }^{37}$

Luego de la desaparición del socialismo este-europeo el rango de países que puede tomarse para el estudio de la forma de gobierno se reduce a China, Corea del Norte, Cuba y Vietnam, cada uno de los cuales posee determinantes históricas específicas que condicionan su sistema político y repercuten en su modelo de gobierno.

No obstante, antes de continuar con el análisis es imprescindible plantear algunos de los rasgos esenciales del esquema organizacional-funcio-

35 Albania 1946, Bulgaria 1947, Checoslovaquia 1948, Alemania 1949, Polonia 1952, Rumania 1948, Hungría 1949, Yugoslavia 1946.

${ }^{36}$ Albania 1976, Bulgaria 1971, Checoslovaquia 1960 (reformada en 1968), Alemania 1968 (reformada en 1974), Polonia 1976 (reformada en 1980 y 1983), Rumania 1965 (reformada en 1986), Hungría 1972 (reformada en 1975 y 1983), Yugoslavia 1953 (reformada en 1963, 1968, 1974 y 1981), uRSs 1977.

${ }^{37}$ Cfr. M. N. Marchénco, J. Fernández Bulté, et al. Op. cit., pp. 260ss; Diego Cañizares Fernando, $0 p$. cit., pp. 248ss. 
nal del aparato estatal en estos países, los que en general también fueron caracteres de los países socialistas europeos:

1. Negación de la tripartición de poderes como principio organizacional de los órganos superiores del Estado.

La teoría socialista reconoce la existencia de una pluralidad de órganos estatales con distintas funciones engarzados bajo una unidad de poder que se deposita en la asamblea parlamentaria, lo que constituye el principio armador del andamiaje estatal.

La noción de la unidad de poder por lo general no es refrendada como tal en las constituciones, sino que queda patentizada a través del principio del centralismo democrático, que sí es explicitado con mayor o menor extensión en los textos. Éste sostiene la verticalidad y obligatoriedad de las decisiones desde los órganos superiores a los inferiores y consecuentemente la posibilidad de revocación de los acuerdos de estos últimos, lo que condensa la noción de que la asamblea parlamentaria es la instancia suprema del poder.

2. Enfoque del Parlamento como órgano legislativo y como instancia suprema del poder político público.

En este sentido, vale señalar que la teoría del Estado marxista negó los resortes sobre los que se erigía el parlamentarismo burgués y en consecuencia argumentó una plataforma funcional de este órgano totalmente distinta.

De esta manera, las notas esenciales de la concepción socialista de este órgano son: conformación del Parlamento como asamblea representativa de toda la sociedad a partir de integrarse no por criterios partidistas sino de representación de la complejidad del tejido social de la nación; función legislativa y constitucional de la misma a la par de poseer una dimensión política, de manera que deviene en concilio para la legitimación de las políticas y estrategias nacionales; no profesionalización en la actividad política de sus miembros, quienes en general continúan desempeñando el oficio o profesión que poseen; composición proporcional al número de habitantes, lo que le impregna una permanente tendencia a crecer en el número de integrantes; funcionamiento durante breves periodos al año, generalmente dos; estructuración de un Comité o Presidencia para su representación formal durante los periodos inter-sesiones y configuración unicameral de la misma.

De esta manera la asamblea se erige en el vértice del mecanismo estatal 
al tener capacidad para diseñar la política interior y exterior, realizar los altos nombramientos del Estado y ejercer la más alta fiscalización sobre el funcionamiento de todos los órganos.

En China esta función la desempeña la Asamblea Popular Nacional y en Vietnam la Asamblea Nacional, las que delegan sus atribuciones cuando no sesionan en un Comité Permanente integrado por el presidente, los vicepresidentes, el secretario y otros miembros. Este órgano ejerce gran cantidad de atribuciones en representación de la Asamblea.

En Corea del Norte está depositada en la Asamblea Suprema del Pueblo, sin que exista un organismo reducido para la representación del órgano durante el lapso inter-sesiones, cuestión que en la práctica la desempeña la presidencia de la asamblea.

3. Desempeño de la función ejecutiva por un órgano colegiado cuya denominación e integración en la historia del constitucionalismo socialista varió de acuerdo a cada país, aunque por lo general fue reconocido como Presídium por la denominación que el mismo adquirió en el modelo soviético ${ }^{38}$ y su composición osciló entre 15 y 25 integrantes.

Hay que agregar, no obstante, que en algunos países socialistas subsistió la figura del presidente como titular del Ejecutivo, como en los casos de Polonia y Checoslovaquia, en donde perduró hasta 1952, Alemania hasta 1960, Rumania, en donde se instituyó a partir de 1974 junto a un órgano colectivo denominado Consejo de Estado y Yugoslavia en donde se retomó en 1953.

Este órgano es elegido por la asamblea parlamentaria y se enfoca conceptualmente como institución que se le subordina y ejecuta sus decisiones, a la par que se erige en la suprema representación del Estado. Así, asume la cualidad de máxima institución de poder que detenta constitucionalmente la asamblea y con ello incluso su capacidad legislativa.

Eso provoca que, dada la brevedad existencial de las asambleas parlamentarias y la alta composición que en general poseen, esta institución se convierte en realidad en la clave de bóveda del andamiaje estatal.

En Corea del Norte la institución se nombra Presídium y éste está integrado por un presidente, un vicepresidente, un secretario y otros miembros que no fija la Constitución. Este órgano colegiado tiene un

${ }^{38}$ En Checoslovaquia se denominó Oficina Presidencial de la Asamblea, en Hungría Consejo de la Presidencia y en los demás países Consejo de Estado. Por encima de la integración promedio señalada se puede citar al Presídium de la URSS, conformado por 39 miembros y la Oficina de la Presidencia de Checoslovaquia, integrada por 40 (20 por cada cámara parlamentaria) 
presidente que ostenta la representación del mismo y con ello del Estado, conformándose con atribuciones propias que lo alejan de ser un simple primus interpares.

China y Vietnam por su parte conservan la figura presidencial como titular del Estado, elegidos en ambos casos por la Asamblea Nacional y con responsabilidad ante ésta. En general poseen funciones protocolarias al estilo de un jefe de Estado parlamentario.

Entre las funciones de estos jefes de Estado en ningún caso se contempla la posibilidad de que disuelva a la asamblea legislativa.

4. Desenvolvimiento de la función de gobierno por un órgano denominado Consejo de Estado en China, Gabinete en Corea y Gobierno en Vietnam. Éstos se conforman por el primer ministro, los viceprimeros ministros, los ministros y otros miembros.

Estos órganos son designados por las diferentes asambleas parlamentarias y sus miembros son responsables ante éstas, pudiendo ser depuestos en cualquier momento. Vale señalar que la designación no crea el vínculo de responsabilidad política al estilo del parlamentarismo occidental, por lo que no hay investidura ni exposición del programa de gobierno a desarrollar. De igual manera, tampoco se configura ningún mecanismo de control específico que derive en dimisión.

Cuando las asambleas no sesionan, los ministros son responsables ante el órgano ejecutivo colegido en Corea, el que puede designar a otros titulares. En el caso de Vietnam y China ante el Comité Permanente de la Asamblea Nacional.

Sus miembros, por lo demás, en ninguno de los países que se comentan son necesariamente integrantes de la asamblea. Sólo la Constitución de Vietnam señala que el primer ministro debe de ser diputado a la asamblea.

A pesar de como se observa, estos rasgos marcan un diapasón en el que resulta muy difícil emplear el mismo sistema conceptual de formas de gobierno que ha condensado la práctica y la teoría del derecho constitucional comparado; en nuestra opinión es preferible asumir el reto que continuar en la inopia doctrinal de sólo admitir la atipicidad de la forma de gobierno socialista.

Sobre esta base, consideramos que en China y Vietnam se ha adoptado un modelo de gobierno sobre las bases del parlamentarismo, con todos los matices que se han comentado y que generan un parlamentarismo mutatis mutandi. 
En Corea del Norte existe una forma de gobierno que denominaríamos como semiconvencional, a partir de los siguientes rasgos: concepción de la asamblea parlamentaria como máximo órgano de poder; existencia de un órgano ejecutivo colegiado elegido por la asamblea parlamentaria; legitimación de un premier del órgano ejecutivo colegiado que a los efectos de representación internacional funge como titular del Ejecutivo; no existencia de mecanismos de control político específicos de la asamblea parlamentaria sobre el Ejecutivo que conlleve a la dimisión de ésos.

A la par, este país presenta como características que lo diferencian del típico modelo convencional suizo, las siguientes: el órgano ejecutivo colegiado asume la autoridad y competencias de la asamblea parlamentaria durante los periodos en que ésta no sesiona, lo cual unido a la efímera vida parlamentaria de esta institución convierte al Ejecutivo en el centro del andamiaje institucional y a su actividad legislativa en la más importante fuente formal de derecho. Junto a esto, la existencia de un órgano de gobierno específico.

\section{La forma de gobierno en Cuba a tenor de la Constitución de 1976}

La Constitución de 1976 siguió de manera general en la confección de su dogmática los esquemas acendrados por el constitucionalismo socialista, alejándose consecuentemente del diseño institucional que había existido en los textos anteriores de su historia constitucional, que en puridad tampoco eran nada autóctonos y podían ubicarse dentro de los moldes del constitucionalismo liberal y en particular del norteamericano.

No obstante, hay que agregar que en la historia constitucional cubana existía el antecedente devenido del constitucionalismo mambí de diseñar el esquema organizacional sobre la base de concentrar el poder en un órgano que se erigía con facultades ejecutivo-gubernativas y legislativas.

A partir de aquí y de lo comentado en el acápite anterior puede abordarse con mayor exactitud la forma de gobierno dibujada por la Constitución cubana de 1976.

Este texto plantea un esquema institucional del poder a nivel superior integrado por la Asamblea Nacional, el Consejo de Estado, el presidente del Consejo de Estado y el Consejo de Ministros.

La Asamblea Nacional es el órgano parlamentario en tanto posee la función legislativa, pero a ello une otras atribuciones que en el enfoque occidental del derecho constitucional no estarían ubicadas en esta institución: 
a) Acordar reformas de la Constitución conforme a lo establecido en el artículo 137; c) decidir acerca de la constitucionalidad de las leyes, decretos-leyes, decretos y demás disposiciones generales; m) elegir al presidente, al vicepresidente y a los demás jueces del Tribunal Supremo Popular; n) elegir al fiscal general y a los vicefiscales generales de la República; $p$ ) ejercer la más alta fiscalización sobre los órganos del Estado y del Gobierno; q) conocer, evaluar y adoptar las decisiones pertinentes sobre los informes de rendición de cuenta que le presenten el Consejo de Estado, el Consejo de Ministros, el Tribunal Supremo Popular, la Fiscalía General de la República y las Asambleas Provinciales del Poder Popular. ${ }^{39}$

De esta forma, queda claro que además de legislar esta institución deviene en órgano supremo del poder, lo que está sustentado teóricamente en que la misma es representación del poder soberano radicado en el pueblo.

La Asamblea Nacional tiene un mandato de seis años y tiene dos periodos de sesiones al año, instituyéndose en su lugar "el Consejo de Estado [que] es el órgano [...] que la representa entre uno y otro periodo de sesiones, ejecuta los acuerdos de ésta y cumple las demás funciones que la Constitución le atribuye". ${ }^{40}$

La Constitución en ningún precepto menciona a la función ejecutiva ni deposita ésta expresamente en un órgano, no obstante queda claro que la misma es desempeñada por el Consejo de Estado a tenor de lo señalado anteriormente y de que además éste órgano, "a los fines nacionales e internacionales, ostenta la suprema representación del Estado cubano". ${ }^{41}$

Es así que esta institución deviene con un triple papel en tanto órgano supremo del poder (representa a la Asamblea Nacional en los periodos inter-sesiones, con lo cual asume sus atribuciones que une a otras propias que denotan la posibilidad de intervenir en cualquier actividad estatal), institución legislativa (dicta decretos-leyes) y agencia ejecutiva (ejecuta e impulsa en su desarrollo los acuerdos, disposiciones y políticas adoptados en las sesiones de la Asamblea). Esto la convierte en el centro del andamiaje estatal.

El Consejo de Estado está conformado por el presidente, el primer vi-

\footnotetext{
${ }^{39}$ Constitución de la República de Cuba, Revisada y concordada por la Dirección de Legislación y Asesoría del Ministerio de Justicia, Minjus, La Habana, 2005, pp. 45-75

${ }^{40}$ Ibid., p. 51, Art. 89.

${ }^{41}$ Idem.
} 
cepresidente, cinco vicepresidentes, el secretario y 23 miembros más, funcionando de manera colegiada.

El presidente del Consejo de Estado posee funciones propias en tanto cabeza de este órgano y del Consejo de Ministros a su vez, cuestión que le otorga un protagonismo en el funcionamiento del Estado y lo aleja de ser un primus interpares:

a) representar al Estado y al Gobierno y dirigir su política general; b) organizar y dirigir las actividades y convocar y presidir las sesiones del Consejo de Estado y las del Consejo de Ministros; c) controlar y atender al desenvolvimiento de las actividades de los ministerios y demás organismos centrales de la Administración; ch) asumir la dirección de cualquier ministerio u organismo central de la Administración; d) proponer a la Asamblea Nacional del Poder Popular, una vez elegido por ésta, los miembros del Consejo de Ministros; e) aceptar las renuncias de los miembros del Consejo de Ministros, o bien proponer a la Asamblea Nacional del Poder Popular o al Consejo de Estado, según proceda, la sustitución de cualquiera de ellos y, en ambos casos, los sustitutos correspondientes; f) recibir las cartas credenciales de los jefes de las misiones diplomáticas extranjeras; g) desempeñar la Jefatura Suprema de las Fuerzas Armadas Revolucionarias; h) presidir el Consejo de Defensa nacional; i) decretar el estado de emergencia en los casos previstos por esta Constitución, dando cuenta de su decisión, tan pronto las circunstancias lo permitan a la Asamblea Nacional del Poder Popular o al Consejo de Estado, de no poder reunirse aquélla a los efectos legales procedentes; j) firmar los decretos-leyes y otros acuerdos del Consejo de Estado y ordenar su publicación en la Gaceta Oficial de la República; k) las demás que por esta Constitución o la Asamblea se le atribuyan. ${ }^{42}$

El Consejo de Ministros, por su parte, es el "máximo órgano ejecutivo y administrativo y constituye el Gobierno de la República". ${ }^{43}$ Está integrado por el presidente que, como ya se ha dicho, es también el presidente del Consejo de Estado, el primer vicepresidente, los vicepresidentes, el secretario y los demás miembros, no señalando la Constitución una integración cerrada.

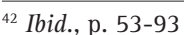

${ }^{43}$ Ibid., p. 55-95. 
Sus miembros son designados por la Asamblea Nacional a propuesta del presidente del órgano y cuando la misma no sesiona evidentemente el Consejo de Estado queda investido con tal función y con la correspondiente capacidad de sustituirlos.

En este sentido, la Constitución plantea sólo como mecanismo de interrelación entre el mismo y la Asamblea Nacional el que la misma conoce, evalúa y adopta las decisiones pertinentes sobre los informes de rendición de cuentas que le presenta éste.

Parte de los integrantes del Consejo de Ministros integran un organismo más reducido reconocido como Comité Ejecutivo, el que puede decidir sobre las cuestiones encomendadas a esta institución en los periodos que median entre las reuniones ordinarias de éste, razón por la que algunos estudiosos han reconocido al mismo como un órgano independiente dentro del aparato de gobierno. ${ }^{44}$

Sobre la base de este diseño orgánico-funcional puede señalarse que la Constitución de 1976 en Cuba diseña una forma de gobierno semiconvencional:

- Concepción de la Asamblea Nacional no sólo como ente legislativo sino además como máximo órgano de poder del Estado.

- Existencia de un órgano ejecutivo colegiado denominado Consejo de Estado.

- Elección del Consejo de Estado por la Asamblea Nacional.

- Conformación del Consejo de Estado como órgano de la Asamblea Nacional, la que puede conocer, evaluar y tomar decisiones sobre los informes que le presente, a la vez que revocar sus actos normativos.

- Los miembros del Consejo de Estado no están limitados a ejercer un solo mandato, sino que de acuerdo al resultado de su labor pueden ser reelectos indefinidamente.

- Legitimación de un premier del Consejo de Estado que a los efectos de representación internacional funge como representante del Estado.

- No existencia de mecanismos de control político específicos de la Asamblea Nacional sobre el Consejo de Estado o el Consejo de Ministros que pueda desembocar en la dimisión de sus miembros.

- Imposibilidad de que el Consejo de Estado disuelva la Asamblea Nacional bajo ninguna circunstancia.

Al paralelo de éstos, se presentan otros rasgos que matizan la dinámica del sistema convencional, ellos son:

${ }^{44}$ Juan Fernández Paz, "Sistema jurídico de gobierno", Revista Cubana de Derecho, No. 28, Año xvı, Unión Nacional de Juristas de Cuba, La Habana, 1987, p. 3. 
- El Consejo de Estado detenta la autoridad y competencias de la Asamblea Nacional durante los periodos en que ésta no sesiona.

- Los miembros del Consejo de Estado forman parte de la Asamblea Nacional, funcionando ello como requisito para su elección.

- Existencia del Consejo de Ministros como agencia especializada de administración y ejecución, independiente del Consejo de Estado.

- Protagonismo del presidente del Consejo de Estado al ser a su vez presidente del Consejo de Ministros y tener asignadas un grupo de atribuciones en la Constitución que lo plantean no sólo como un primus interpares que representa a la nación a los fines internacionales o coordina la labor del órgano. 